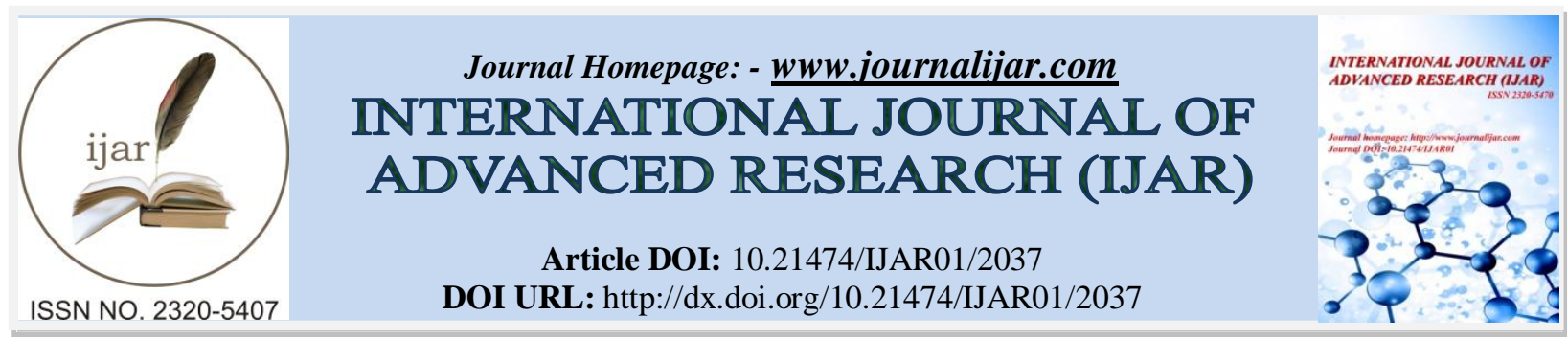

RESEARCH ARTICLE

\title{
PLASMA MAGNESIUM STATUS IN TYPE 2 DIABETIC PATIENTS WITH AND WITHOUT DIABETIC NEUROPATHY.
}

Prof .Fawzy Megahed Khalil, Prof . Mohamed Ahmed El Assal, Prof.Ass. Ahmed Mohamed Hussein Dabour, Lec. Mohamed Abd El Latif, Lec. Afaf Fathi Khamiss and Ass. Lec. Rasha Mohamed abd El-Hady. Internal medicine department, Faculty of medicine, Benha University.

\section{Manuscript Info}

Manuscript History

Received: 27 September2016

Final Accepted: 12 October 2016

Published: October 2016

Key words:-

hypomagensemia, complications of diabetes type 2 ,poor glycemic control, diabetic neuropathy.

\section{Abstract}

Background :Diabetic peripheral neuropathy (DPN) is a diabetes mellitus (DM) induced disorder of the peripheral nervous system and is characterized by pain and loss of sensation due to symmetrical degeneration of distal peripheral nerves.Studies have shown that magnesium levels are lower in patients with diabetes compared with nondiabetic controls.

Objective: to study plasma magnesium status in type 2 diabetic patients with and without diabetic neuropathy .

Subjects and Methods; A sample of 110 subjects were included and devided into: group (I) ; including 10 patients without diabetes as control ,group(II)including 74 patients of type 2 diabetic with clinically evident neuropathy ; group (III); including 26 patients of type 2 diabetics without clinically evident neuropathy .All patients subjected to detailed medical history, complete clinical examination , fundoscopic examination, laboratory investigations including; RBS; plasma magnesium Levels , HbA1C,Urine analysis, 24 hrs. urinary albumin, estimated GFR., excluding patients with renal faluire , acute myocardial infarction, patients on diuretics, aminoglycosides and other drugs causing magnesium supplements and magnesium containing antacids, pregnant and lactating women.

Results: the comparative study consists of 10 patients without diabetes as control(groupI), 74 patients of type 2 diabetes with clinically evident neuropathy (groupII), 26 patients of type 2 diabetes without clinically evident neuropathy.the avaeage range of plasma magnesium level among 3 groups was $2.12 \pm 0.15,1.47 \pm 0.30$, $1.93 \pm 0.26$ respectively, there is asignificantly statistical difference among the three groups $(\mathrm{p}<0.001)$.

Conclusion; There is association of hypomagnesaemia with poor glycemic control and also with various long-term complications of diabetes mellitus especially diabetic neuropathy .

Copy Right, IJAR, 2016,. All rights reserved.

\section{Introduction:-}

Diabetes Mellitus is a metabolic and endocrine disorder characterized by both insulin deficiency and insulin resistance. Most of the cases are diagnosed as Type 2 diabetes. Type 2 diabetes has become a leading cause of 
morbidity and mortality across the world. Diabetic complication are likely because of its metabolic changes . chronic complications include majorly neuropathy, nephropathy and retinopathy .(ADA,2014)

Diabetic peripheral neuropathy (DPN) is a diabetes mellitus (DM) induced disorder of the peripheral nervous system ( Deli et al.,2014) and is characterized by the pain and loss of sensation due to symmetrical degeneration of distal peripheral nerves. The symptoms will deteriorate with the progression, which may result in diabetic ulcers or even no traumatic amputation.

Statistics revealed that the incidence of DPN was as high as 30\%, 60\%, and 90\% at 5, 10, and 20 years after diagnosis of DM, and foot injury had occurred in 50\% of DPN patients when they were asymptomatic (Boulton et al.,2005)

Mineral ions play specific roles in our body. One of the important mineral cation is magnesium $(\mathrm{Mg})$, which is a cofactor in glucose transporting mechanism of the cell membrane of nearly or more than cellular enzymatic systems, Magnesium is the second most common intracellular cation, 300 Many studies have been shown reduced magnesium concentrations in diabetic adults ,Intracellular magnesium is having an important role in insulin action regulation, insulin-mediated glucose uptake, and vascular tone. In diabetic patient's reduced intracellular $\mathrm{Mg}$ concentrations results in abnormal tyrosine-kinase activity, post receptorial impairment in insulin action, and insulin resistance worsening.(Mutlu, et al.,2007.) .

Studies have shown that magnesium levels are lower in patients with diabetes comparedwith non diabetic controls.(Limaye et al.,2011). The association of hypomagnesaemia with poor glycemic control and also with various long-term complications of diabetes mellitus have been reported. (Pham et al., 2007)

\section{Subjects And Methods:-}

This study was conducted on 110 subjects including 100 type 2 diabetic patient and 10 non diabetic subjects admitted to the Department of Internal Medicine, Benha University Hospital within the period between june 2015 to june 2016 .

Patients with type 2 diabetes mellitus aged between 30 to 70 years with or without clinically evident diabetic neuropathy .

A sample of 110 subjects were included and devided into: group (I) ; including 10 patients without diabetesascontrol ,group(II)including 74 patients of type 2 diabetic with clinically evident neuropathy ; group (III); including 26 patients of type 2 diabetics without clinically evident neuropathy .All patients subjected to detailed medical history, complete clinical examination, fundoscopic examination, laboratory investigations including; RBS; plasma magnesium Levels, HbA1C,Urine analysis, $24 \mathrm{hrs}$. excluding patients with renal faluire, acute myocardial infarction, patients on diuretics, aminoglycosides and other drugs causing magnesium supplements and magnesium containing antacids, pregnant and lactating women.

\section{Results:-}

Our study was conducted on 110 subjects and divided into three groups as mentioned before in subjects \& methods .the three groups were compared regarding age,sex,duration, $\mathrm{HbA1c}, \mathrm{S} . \mathrm{Mg}$,clinically evedint neuropathy ,retinopathy and nephropathy.table1According to our study There was statistically significant difference between the three groups as regard mean Age and duration of DM.

The study also showed that There was statistically significant difference between the three groups as regard HbA1c and RBS ( $\mathrm{P}$ value $<0.001)$.

The study also showed There was statistically significant difference between the three groups as regard S Mg (P value<0.001). , the lowest level of S Mg with groupII (patients with clinically evident neuropathy) .(fig 1)

The study showed also that The average percentage of Clinically evident diabetic neuropathy among 3 groups was $0 \%, 74 \%$ and $0 \%$ respectively. 
There was statistically significant difference between the three groups (P value $<0.01$ ) regarding Clinically evident neuropathy (fig 2).

Table 1:- Distribuation of the studied groups.

\begin{tabular}{|l|l|l|}
\hline & mean \pm SD & Range \\
\hline Age & $55.51 \pm 12.61$ & $5-77$ \\
\hline Sex $n(\%)$ & & \\
Male & $44(40.0)$ & \\
Female & $66(60.0)$ & $0-25$ \\
\hline Duration & $9.95 \pm 6.72$ & $12-480$ \\
\hline RBS & $234.35 \pm 91.8$ & $3.8-11.5$ \\
\hline HbA1c & $7.6 \pm 1.78$ & $1-2.6$ \\
\hline S Mg & $1.64 \pm 0.37$ & \\
\hline Clclinically evident neuropathy & $74(67.3)$ & \\
Yes & $36(32.7)$ & \\
No & & \\
\hline Retinopathy & & \\
Yes & $64(58.2)$ & \\
No & $46(41.8)$ & \\
\hline Nephropathy & & \\
Yes & $37(33.6)$ & \\
No & $73(66.4)$ & \\
\hline
\end{tabular}

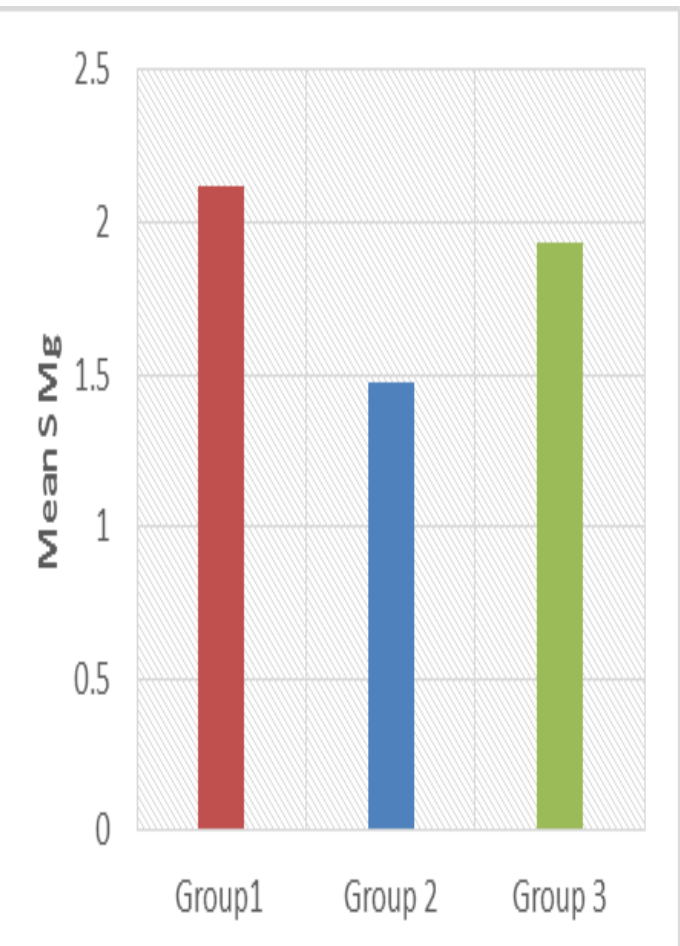

Figure 1:- Comparison between the studied groups in type 2 diabetes mellitus regarding mean $\mathrm{S} \mathrm{Mg}$. 


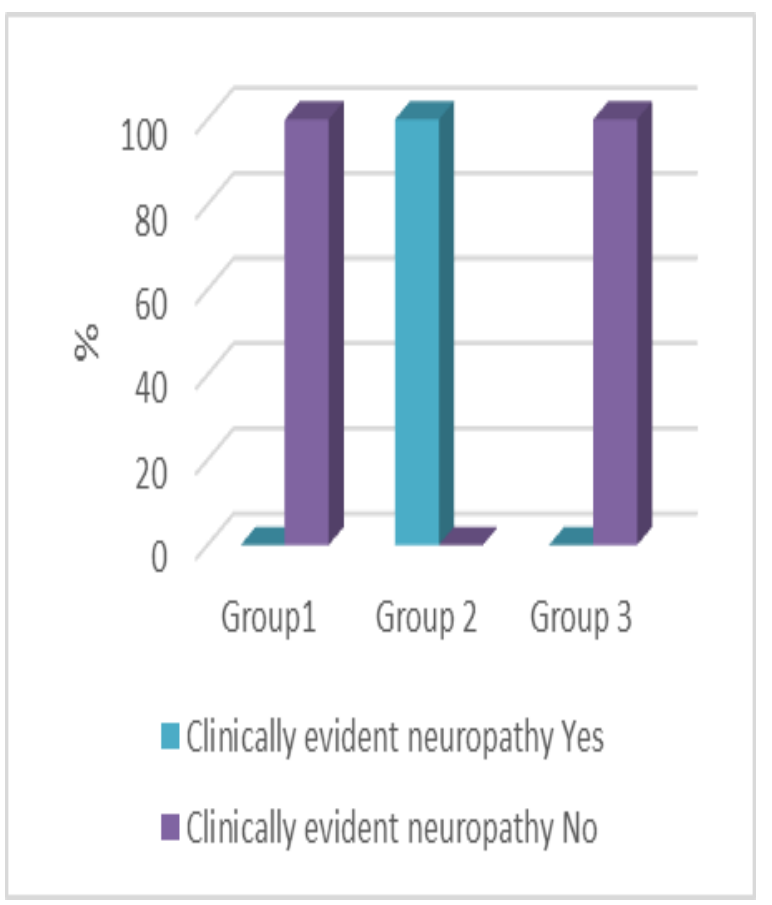

Figure 2:- Comparison between the studied groups regarding clinically evident diabetic neuropathy.

\section{Discussion:-}

Our study enrolled 100 type 2 diabetic patients and 10 non diabetic patients attending to Banha university hospital, internal medicine department . the patients were classified into 3 categories, non diabetic patient without neuropathy ,diabetic patient with neuropathy ,diabetic patient without neuropathy respectively. Serum magnesium, random blood glucose and glycated hemoglobin were determined. Among the 110 patients there were 10 patient (non diabetic) without neuropathy (group I) 74 patients of type 2 diabetes mellitus with diabetic neuropathy (group II) and 26 patients of type 2 diabetes mellitus without diabetic neuropathy (groupIII) . There is a significant statistical differences (P-value $<0.01$ ) between diabetic neuropathy (group II) and control group(group I) and group II in serum magnesium, random blood glucose, glycated hemoglobin and duration of diabetes. The average range of serum Magnesium level among 3 groups was, $2.12 \pm 0.15,1.47 \pm 0.30$ and $1.93 \pm 0.26$ respectively, There is significant difference among 3 group $(\mathrm{P}<0.05)$, low level of serum magnesium with group II (diabetic patient with neuropathy) and high level with group I( non-diabetic patient without neuropathy).

Serum magnesium level decreased in patients with diabetic neuropathy with lowest level being observed in patients with neuropathy associated with diabetic retinopathy and nephropathy .

The results of the current study were agreed with (Rayssiguier et al.,2010); Study of serum magnesium level in diabetic patients with microvascular complications including diabetic neuropathy, retinopathy and nephropathy reveal that the serum magnesium levels were significantly lower in patients with microvascular complications compared to diabetics without complications.

The comparative study was done on 50 diabetic subjects ( 25 without microvascular complications, 25 with micro vascular complications).serum magnesium was compared between the two groups

Both groups were subjected to estimation of biochemical parameters., statistically observed .In this study there was found that diabetics with micro vascular complications had significantly lower level of serum magnesium $(1.46 \pm 0.32)$ compared to diabetics without micro vascular complications $(1.92 \pm 0.25)$.

The results of the current study were agreed also with (Pico' $n$ et al.,2012) 
Study of serum Magnesium levels in type 2 Diabetes Mellitus, This study demonstrated that Low Mg2+ status is common in Type 2 diabetes mellitus patients when compared to non diabetic controls. It may be prudent in clinical practice to periodically monitor plasma $\mathrm{Mg} 2+$ concentration in diabetic patients. If plasma $\mathrm{Mg} 2+\mathrm{is}$ low, an intervention to increase dietary intake of magnesium may be beneficial. This study was done in randomly chosen 100 Type 2 diabetic patients, and 100 non diabetic age / sex matched controls age group 30 to 70 years attending diabetic clinic. All patients and controls underwent thorough clinical examination and required laboratory investigation.

\section{Conclusion:-}

Hypomagnesaemia is likely among patients with type 2 diabetes mellitus. Long term complications especially neuropathy may have hypomagnesemia as a contributing factor.Moreover, because Mg is crucial in DNA synthesis and repair. It is possible that $\mathrm{Mg}$ deficiency may interfere with normal cell growth and regulation of apoptosis. We, therefore, conclude that serum magnesium level decreased in patients with diabetic neuropathy with lowest level being observed in patients with advanced neuropathy. Because $\mathrm{Mg} 2+$ depletion reduces insulin sensitivity and may increase risk of secondary complications, Hence it is prudent that serum magnesium levels are carefully monitored in diabetic patients.

\section{Acknowledgements:-}

I would to express my sincere gratitude and great appreciation to faculty of medicine, Benha university to provide help and to the Head, Department of internal medicine,Benha University, to provide all necessary facilities and help.

\section{References:-}

1. American Diabetes Association (2014). Diagnosis and classification of diabetes mellitus. Diabetes Care ;37(Suppl. 1) s81-s90

2. Boulton A. J. M., Vinik A. I., Arezzo J. C., et al. (2005): Diabetic neuropathies (a statement by the American Diabetes Association. DiabetesCare. ;28(4):956-962.doi: 10.2337/diabetes care.28.4.956.

3. Deli G., Bosnyak E., Pusch G., et al., (2014); Diabetic neuropathies:diagnosis and management of .Neuroendocrinology. ;98(4):267-280.doi:10.1159/000358728.

4. Limaye CS, Londhey VA, Nadkar MY, et al.,(2011). Hypomagnesemia in critically ill medical patients. J Assoc P hysicians India. ; 59:19-22.

5. Mutlu M, Argun M, Kilic E,et al.,(2007): Magnesium, zinc and copper status in osteoporotic, osteopenic and normal post-menopausal women. J Int Med Res. ; 35: 692-695.

6. Pham PC, Pham PM, Pham SV, et al.,(2007). Hypomagnesemia in patients with type 2 diabetes.Clin J Am Soc Nephrol. ; 2:366-73.

7. Pico' n MJ, Murri M, Mun A,et al.,,(2012): Hemoglobin A1c versus oral glucose tolerance test in postpartum diabetes screening. Diabetic care;35:1648-1653

8. Rayssiguier Y, Libako P, Nowacki W, Rock E,(2010); Magnesium deficiency and metabolic syndrome: stress and inflammation may reflect calcium activation. Magnes Res. ; 23: 73-80. 